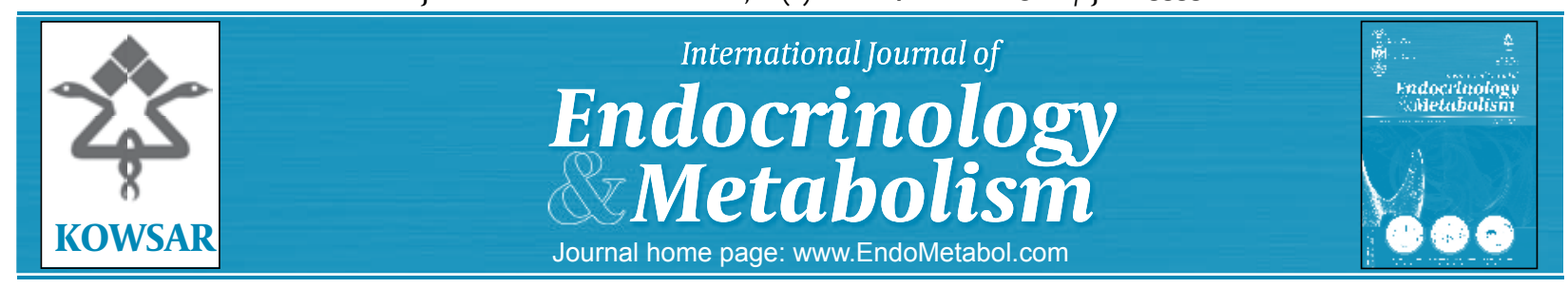

\title{
Effect of Progressive Aerobic and Resistance Exercises on the Pulmonary Functions of Individuals With Type 2 Diabetes in Nigeria
}

\author{
Oluwaseyi Osho $^{1^{*}}$, Sunday Akinbo ${ }^{1}$, Abraham Osinubi $^{2}$, Olajide Olawale ${ }^{1}$ \\ ${ }^{1}$ Department of Physiotherapy, College of Medicine, University of Lagos, Lagos, Nigeria \\ ${ }^{2}$ Reproductive Endocrinology Unit, Department of Anatomy, College of Medicine, University of Lagos, Lagos, Nigeria
}

\begin{tabular}{l}
\hline A R T I C L E I N F O \\
\hline Article type: \\
Original Article \\
\hline Article history: \\
Received: 01 Nov 2011 \\
Revised: 20 Dec 2011 \\
Accepted: 28 Dec 2011 \\
\hline
\end{tabular}

Keywords:

Exercise

Resistance Training

Lung

Hemoglobin A, Glycosylated

Diabetes Mellitus, Type 2

\begin{abstract}
A B S T R A C T
Background: The lungs are end organs that are adversely affected in Nigerian adults with type 2 diabetes. Assessment and monitoring of the progress of pulmonary functions postexercise prescription is paramount for optimal feedback on a patient's progress.

Objective: This study was designed to investigate the pulmonary responses of individuals with T2DM to progressive aerobic exercises and resistance exercises (PAREs) and assess changes at specified points in the intervention period.

Patients and Methods: A total of 60 subjects ( 36 females and 24 males) aged 40-75 years were consecutively recruited into this randomized control study, which comprised a PARE and a control group. Outcome measures, which included pulmonary parameters (oxygen uptake $\left(\mathrm{VO}_{2}\right.$ max), forced vital capacity (FVC), forced expiratory volume in one second (FEV1) ) and anthropometric parameters (body mass index (BMI), waist circumference (WC), and waist hiP ratio (WHR), were assessed at baseline and at the end of Weeks 4, 8, and 12 of the intervention period. Glycosylated hemoglobin level (HbAlc) was assessed at baseline and at the end of Week 12. Data were analyzed using descriptive statistics and inferential statistics. Level of significant was set at $P<0.05$

Results: Mean $\mathrm{VO}_{2}$ max, FEV1, and FVC increased as early as 4 weeks postintervention. Significant improvements in these variables were noted in subjects $(P<0.05)$. WC and HbA1C were significantly reduced $(P=0.03$ and 0.001 , respectively) following intervention. Significant changes in pulmonary variables occurred from Week 8 week following the post hoc analysis. Conclusions: PARE is beneficial in the management of pulmonary complications in adult Nigerian T2DM patients. PARE for at least 4 weeks may improve the pulmonary function of individuals with T2DM. However, postexercise prescription assessment may be commenced 8 weeks post intervention.
\end{abstract}

Copyright $\odot 2012$ Kowsar M.P. Co. All rights reserved.

- Implication for health policy/practice/research/medical education:

Pulmonary complications in type 2 diabetes are a major health issue of concern. Management and progress monitoring post exercise intervention is paramount for optimal feedback. Results of this article are useful for physiotherapist, endocrinologist, diabetes educators and clinicians in cardiopulmonary field of study.

- Please cite this paper as:

Osho OA, Akinbo SRA, Osinubi AAA, Olawale OA. Effect of Progressive Aerobic and Resistance Exercises on the Pulmonary Functions of Individuals With Type 2 Diabetes in Nigeria. Int J endocrinol Metab. 2012;10(1): 411-7. DOI: 10.5812/ijem.3333

* Corresponding author: Oluwaseyi Osho, Department of Physiotherapy, Faculty of Clinical Sciences, College of Medicine of the University of Lagos, Lagos, Nigeria. Tel:+1-4037191404.Email: oaosho@cmul.edu.ng

DOI:10.5812/ijem.3333

Copyright @2012 Kowsar M. P. Co. All rights reserved.

\section{Background}

Diabetes Mellitus (DM) is a significant health problem, predisposing one to markedly increased morbidity and mortality in Nigeria $(1,2)$. A study of the prevalence of DM showed that T2DM is the most common type of DM, accounting for about $90 \%$ of cases (3). World wide, approximately 200 million people have Type 2 Diabetes Mellitus 
(T2DM), a prevalence that has been predicted to increase to 366 million by 2030 (4). Crude prevalence rates of $7.7 \%$ and $5.7 \%$ were estimated for males and females in Port Harcourt, Nigeria (5). Furthermore, the national prevalence of DM has also been estimated to be $6.8 \%$ in adult Nigerians aged older than 40 years (6).

The link between reduced lung function and DM has been described for many years, although the clinical significance of this association is not known $(7,8)$. Possible links between respiratory impairments in people with DM have been attributed to increased BMI, subsequent loss of respiratory compliance, neuropathies, loss of strength of respiratory muscles, and other confounding variables (8). Biochemical disorders, such as poor glucose control, significantly contribute to the increased risk of pulmonary complications and other morbidities in DM patients $(9,10)$. Rates of pulmonary disease mortality and morbidity are particularly high in this population, thus representing a significant cost for health care systems in Nigeria $(8,9)$. Reduced lung volumes and airflow limitation have also been reported to be chronic complications of T2DM (7-9). The severity of this decrease has been reported to be related to glycemic exposure (11, 12). Poor glucose control has been linked to microvascular complications and reduced ventilatory function of the lungs (10). Airflow limitation is a predictor of death in T2DM, after adjusting for other recognized risk factors $(10,11,13)$.

Exercise has been shown to be a valuable and economical therapeutic modality that can be considered as a beneficial adjunct for DM, especially type 2, noninsulindependent DM $(12,14,15)$. Regular physical exercise of moderate intensity has been reported to be effective in the prevention and delay of the onset of DM and has been proven to increase insulin sensitivity and ameliorate glucose metabolism $(14,16,17)$. A combination of aerobic exercises and resistance training has greater benefits than either aerobic or resistance exercises alone as an adjunct for glycemic control in T2DM patients than either aerobic or resistance exercises alone $(14,15)$.

\section{Objectives}

There are few studies on the effect of PARE in the Nigerian population with T2DM. In addition, no structured exercise program or specified time frame for the assessment of improvement postexercise prescription is in place for people with T2DM. The assessment and monitoring of T2DM patients postexercise prescription is paramount for optimal feedback on their progress and the development of motivational measures in people with T2DM. It is therefore crucial to determine the specific time frame when the therapeutic and beneficial effects of PARE occur to follow the trend of improvements in people with T2DM. This study was designed to investigate the pulmonary responses of individuals with T2DM to PARE, with assessments of changes at specified times in the intervention period.

\section{Patients and Methods}

\subsection{Study Sample}

A total of 60 participants ( 36 females and 24 males) aged 40-75 years were consecutively recruited from the endocrinology unit of the Department of Medicine, Lagos University Teaching Hospital (LUTH), Idi-Araba, Lagos, Nigeria, and Lagos State University Teaching Hospital (LASUTH), Ikeja, Lagos, Nigeria. Pre-intervention screening and clinical examinations were performed by certified physicians to determine study eligibility before random allocation into the PARE or control group using a systematic randomization method. The participants were recruited, based on the following inclusion criteria: established T2DM (not less than 1 year in duration), sedentary lifestyle [score below 3 on the Rapid Assessment of Physical Activity Questionnaire (RAPA) $(18,19)]$, no resistance exercises in the preceding 6 months, and on current insulin therapy. They were nonsmokers and nonalcoholics with no physical restriction in terms of mobility and had no pre-existing pulmonary infections or deformities in the trunk. Patients with severe complications of DM, such as neuropathy, nephropathy, and retinopathy, were excluded from the study. All participants gave written informed consent to participate in this study. Ethical approval was obtained from the Research and Ethics Committee of LUTH and LASUTH, and the study was conducted between January 2010 to March 2011 at the Department of Physiotherapy of LUTH and LASUTH.

\subsection{Instrumentation}

We used the following instruments (the instruments used for this study were): motorized treadmill (Daily Youth, England), medical Microsoft spirometer (Schiller, Switzerland), mercury sphygmanometer (Baumanometer Desk Top model no. 320; W.A. Baum Co., Copiague, $\mathrm{NY}$ ), stethoscope, Accucheck active glucometer and glucometer strips for blood glucose monitoring, combined scale and height meter (Seradon, England), tape measure calibrated in centimeter and inches, rapid assessment of physical activity level questionnaire (RAPA), and weights and sandbags of various sizes. Glycosylated hemoglobin was measured by boronate affinity assay using the NycoCard HbA1c System and a NycoCard HbA1c reader II, Axis Shield PoC (Norway) (measuring range: 3-18\% HbA1c, reference range: $4.5-6.3 \%$ HbA1c). The sample material was 5 $\mu \mathrm{L}$ whole blood, and the level of precision was a coefficient of variation (CV) below $5 \%$ both within and between runs.

\subsection{Study Intervention}

The interventions for the PARE group were validated exercise protocols from previous studies: treadmill protocol at $1 \%$ gradient (20-22) and 1 repetition maximum 
(1RM) for resistance exercise intensity assessment using free weights (23). The control group had no exercise intervention but had an educational session that all other participants in the PARE group participated in. Topics that were considered during the education session included blood glucose monitoring and record keeping, recognition and management of hypoglycemia and hyperglycemia, medication adjustment based on nutrition and activity schedules, weight control and diet modification including meal plan, diabetes complications, and the importance of diabetes control. The participants had these counseling sessions fortnightly during the study period. Monthly rapid assessment of the physical activity levels of the participants in the control group was also done using the rapid assessment of physical activity level questionnaire $(18,19)$ to monitor their physical activity and ensure that they were not engaging in exercises. All subjects maintained their diet and medications throughout the study period.

The glucose levels of PARE participants were checked using a glucometer before and after exercise training as a precaution against hypoglycemia; Borg's rate of perceived exertion was also used to also monitor $=$ exercise intensity. The exercise session included:

\subsubsection{Warm-up Exercises}

All subjects performed 10 minutes of warm-up exercise, which comprised flexibility exercises, involving a range of motion exercises to all joints of the upper and lower limbs and trunk (24). Each joint was moved for 10 repetitions.

\subsubsection{Aerobic Exercises}

The mode of aerobic exercise was a weight-bearing exercise on the treadmill. The participants exercised on treadmill for a period of 20 minutes per session. Subjects were required to initially walk on the treadmill at a speed of $1.5 \mathrm{~km} / \mathrm{hr}$ and a gradient of $0 \%$ to become accustomed with the treadmill (24); the gradient progressed to $1 \%$, which has been established in previous studies to correlate with outdoor walking and compensate for the lack of air resistance in the research ground. (20-22). The speed of the treadmill was left at $3 \mathrm{~km} / \mathrm{hr}$ and increased gradually by $1 \mathrm{~km} / \mathrm{hr}$ every 2 minutes until the subject's heart rate reached a moderate intensity range of $60-80 \%$ of their heart rate reserve (24).

Borg's rate of perceived exertion was also used as a check tool for the exercise intensity; subjects were instructed to describe how they felt based on the scale. They were encouraged to exercise at moderate intensity at 1213 points of the scale, which denoted "somewhat hard." Participants performed aerobic exercises on a treadmill for 20 minutes per session. They commenced exercise at $60 \%$ of their HRR from the Weeks 0 to 4, progressing to $70 \%$ from Weeks 5 to 8 and $80 \%$ from Weeks 9 to 12 to allow for gradual adaptation to the moderate-intensity train- ing. The aerobic exercises was performed over 3 days per week, up to 3 sessions with no more than 2 consecutive days without aerobic exercise per week. Thus, there were 36 total aerobic sessions for the 12 weeks of the study.

\subsubsection{Cool Down Exercises}

Participants cooled down for 5 minutes as they performed the active full range of motion exercises of all joints of the upper limbs, lower limbs, and trunk after the aerobic exercises, after which they rested for $10 \mathrm{~min}$ utes before commencing resistance exercises (23).

\subsubsection{Resistance Exercises}

Resistance exercises of the muscle groups were performed by subjects using dumbbells and sandbags of known weights in each exercise session. The resistance regimen was performed for flexors and extensors of the knees and elbows (23). Weights of different sizes, which depended on the 1-repetition maximum (1RM) of the muscle groups, were considered suitable for the resistance exercises (23). Fifty to seventy percent of this RM, which is the moderate-intensity range, was lifted progressively by the muscle groups (15). The participants also performed strengthening exercises for both hands using rubber balls. They were encouraged to squeeze the ball as strongly as they could (23), performing 12 repetitions per set; 3 sets were considered for the entire muscle groups to have been exercised. A set of 12 repetitions for the back curls and bilateral straight leg raisings were also performed by the participants at comfortable speeds (23). Each set of resistance exercises lasted for about 25-30 seconds. The subjects performed resistance exercises 3 times per week for 12 weeks, for a total of 36 sessions for the study period. Each session lasted for a total duration of about 33 minutes, including a 1-minute recovery period following a set of resistance exercises by each muscle group (24).

\subsection{Outcome Measures}

Sociodemographic data of all subjects were obtained at baseline, including age at last birthday, gender, and duration of DM. All other outcome measures for this study, which included pulmonary and anthropometric variables, were assessed at baseline and at the end of Weeks 4,8 , and 12 . HbA1c was assessed in all subjects at baseline and at the end of Week 12 .

\subsubsection{Anthropometric Measurements}

Weight and height were measured without shoes but with light clothing (shorts or warm-up pants).

- Body mass index (BMI) (kg body weight $\mathrm{m}^{2}$ height) (14) was measured. Body weight was measured to the nearest kilogram using a scale with an incorporated height meter (Seradon, England). Height was measured to the nearest centimeter and was converted to meters. 
- Waist circumference, which is a measure of central obesity, was measured with a tape measure in centimeters as the average of measurements taken after inspiration and after expiration at the midpoint between the lowest rib and the iliac crest (14).

- Waist-hip ratio was determined as the ratio of waist circumference and the circumference of the hips at the trochanter major (14).

\subsubsection{Pulmonary Parameters}

Oxygen uptake, forced vital capacity (FVC), and forced expiratory flow in 1 second (FEV1) were measured. FVC and FEV1 were obtained using a handheld medical spirometer. These pulmonary function tests were done for each participant at a Same time per day. The precise technique of the lung function tests was based on the operating manual of the instrument per the official statement of the American Thoracic Society of Standardization of Spirometry (1987) (25). Subjects were trained about the entire maneuver and were encouraged to practice it before doing the pulmonary function tests. The parameters measured FVC and FEV1.The tests were performed with each subject in the standing position and repeated 3 times after adequate rest. The average value was obtained and recorded. Participants were asked to fully expire air into the spirometer after maximal inspiration. Values obtained from the maximal expiration included FEV1 and FVC.

- FVC was the maximum amount of air that was expired after the maximum inspiration in liters

- FEV1 was the volume of air expired in the first second after maximal inspiration in liters.

- Oxygen uptake $\left(\mathrm{VO}_{2} \mathrm{max}\right)$ of the subjects was obtained by Rockport 1-mile walk test $(26,27)$. The subjects were required to walk for 1 mile as fast as possible on a track. The time taken to complete the 1-mile walk was recorded, and the heart rate was recorded immediately on finishing the walk. The age and gender of the subjects were also documented.

$\mathrm{VO}_{2}$ max was calculated as:
$132.853-(0.0769 \times \mathrm{W})-(0.3877 \times$ Age $)+(6.315 \times$ gender $)-$ (3.2649 x T) - (0.1565 x HR) $(26,27)$.

where $\mathrm{W}=$ weight in pounds (lbs), gender is male $=1$ and female $=0, t=$ time in hundredths of minutes, $\mathrm{HR}=$ heart rate in beats per minutes, and age $=$ age in years .

\subsubsection{Glucose control}

- HbA1c: Blood samples were drawn from the subjects in the fasting state and analyzed by NycoCard HbA1c test (NycoCard reader II, Axis Sheild PoC, made in Norway).

\subsection{Statistical Analysis}

Statistical analysis was done using SPSS 15 (Chicago IL). Analysis of the sociodemographic data was done using descriptive statistics of means and standard deviations. Analysis of variance was used to determine the statistical significance of the variables. A least significance difference post hoc test was carried out to determine the exclusively significant variables. Paired t test was used to analyze HbA1c at baseline and the end of Week 12. The level of significance was set at $P<0.05$.

\section{Results}

Sixty percent of the PARE participants were male while $40 \%$ were female. Fifty five Percent of the Participants in the control group were male while $45 \%$ were female.

Tables 1 and 2 show the pulmonary, glucose control, and anthropometric variables of the PARE and control groups. $\mathrm{VO}_{2} \max$ and FEV1 were significantly different from baseline at Weeks 8 and 12 in the PARE group but not in the control group. FVC, BMI, and WC were also significantly different from baseline in the PARE group but not in the control group. WHR did not differ across weeks in either group.

Table 3 shows the changes in pulmonary and anthropometric variables in the 2 groups at baseline and end of Weeks 4,8 , and 12 of the study period. Mean increases in $\mathrm{VO}_{2}$ max, FVC, and FEV1 in PARE subjects were recorded as early as the fourth week postintervention, and the trend

\begin{tabular}{|c|c|c|c|c|c|c|}
\hline Variables & Baseline & End of $4^{\text {th }}$ Week & End of $8^{\text {th }}$ Week & End of $12^{\text {th }}$ Week & $F$ value & Pvalue \\
\hline \multicolumn{7}{|l|}{ Pulmonary } \\
\hline $\mathrm{VO}_{2} \max ^{\mathrm{a}}(\mathrm{kg} / \mathrm{mL} / \mathrm{min})$ & $21.32 \pm 5.33^{\mathrm{d}}$ & $23.19 \pm 4.82$ & $26.05 \pm 4.58^{c}$ & $28.64 \pm 4.88^{c}$ & 8.58 & $0.00^{\mathrm{b}}$ \\
\hline FVC $^{\mathrm{a}}$ (Litres) & $1.50 \pm 0.22$ & $2.06 \pm 0.49$ & $2.18 \pm 0.53$ & $2.13 \pm 0.57$ & 8.78 & $0.00^{\mathrm{b}}$ \\
\hline FEV1 ${ }^{\mathrm{a}}$ (Litres) & $1.42 \pm 0.27$ & $1.94 \pm 0.44$ & $2.14 \pm 0.54^{c}$ & $2.32 \pm 0.45^{c}$ & 15.89 & $0.00^{b}$ \\
\hline \multicolumn{7}{|l|}{ Biochemical } \\
\hline $\mathrm{HbA1}_{\mathrm{C}}{ }^{\mathrm{a}}(\%)$ & $7.38 \pm 1.23$ & - & - & $6.07 \pm 0.86$ & $\mathrm{~T}=15.28$ & $0.00^{\mathrm{b}}$ \\
\hline \multicolumn{7}{|l|}{ Anthropometric } \\
\hline $\mathrm{BMI}^{\mathrm{a}}\left(\mathrm{kg} / \mathrm{m}^{2}\right)$ & $31.10 \pm 1.20$ & $27.79 \pm 3.27$ & $29.97 \pm 11.96$ & $28.73 \pm 3.16^{c}$ & 0.98 & 0.41 \\
\hline $\mathrm{WC}^{\mathrm{a}}(\mathrm{cm})$ & $100.53 \pm 9.99$ & $93.40 \pm 6.77$ & $95.81 \pm 6.45$ & $98.61 \pm 8.05^{c}$ & 3.11 & $0.03^{b}$ \\
\hline $\mathrm{WHR}^{\mathrm{a}}$ & $0.96 \pm 0.03$ & $0.97 \pm 0.05$ & $0.93 \pm 0.10$ & $0.96 \pm 0.11$ & 1.05 & 0.38 \\
\hline
\end{tabular}

a Abbreviations: $\mathrm{VO}_{2} \mathrm{max}$, Oxygen Uptake; FVC, Forced Vital Capacity; FEV1, Forced Expiratory Volume in One Second; HbA1c, Glycosylated Haemoglobin; BMI, Body Mass Index; WC, Waist Circumference; WHR: Waist Hip Ratio

b significance at $P<0.05$ across the weeks

${ }^{\mathrm{c}}$ significantly different from baseline at $P<0.05$

${ }^{d}$ Data are Presented as Mean \pm SD 


\begin{tabular}{|c|c|c|c|c|c|c|}
\hline Variables & Baseline & End of $4^{\text {th }}$ Week & End of $8^{\text {th }}$ Week & End of 12 ${ }^{\text {th }}$ Week & F value & Pvalue \\
\hline \multicolumn{7}{|l|}{ Pulmonary } \\
\hline $\mathrm{VO}_{2} \max ^{\mathrm{a}}(\mathrm{kg} / \mathrm{mL} / \mathrm{min})$ & $21.43 \pm 5.27^{c}$ & $18.07 \pm 2.41$ & $18.17 \pm 2.86$ & $19.94 \pm 6.15$ & 2.57 & 0.06 \\
\hline FVC $^{\mathrm{a}}$ (Litre) & $1.81 \pm 0.82$ & $1.80 \pm 0.77$ & $1.78 \pm 0.73$ & $2.08 \pm 0.68$ & 0.69 & 0.56 \\
\hline FEV1 $^{\mathrm{a}}$ (Litre) & $1.39 \pm 0.56$ & $1.47 \pm 0.57$ & $1.61 \pm 0.53$ & $1.48 \pm 0.55$ & 0.53 & 0.66 \\
\hline \multicolumn{7}{|l|}{ Biochemical } \\
\hline $\mathrm{HbA1}_{C}{ }^{\mathrm{a}}(\%)$ & $6.95 \pm 1.34$ & - & - & $6.77 \pm 0.71$ & $\mathrm{t}=0.28$ & 0.6 \\
\hline \multicolumn{7}{|l|}{ Anthropometric } \\
\hline $\mathrm{BMI}^{\mathrm{a}}\left(\mathrm{kg}^{2} / \mathrm{m}\right)$ & $33.00 \pm 2.45$ & $34.83 \pm 7.04$ & $32.96 \pm 2.47$ & $32.95 \pm 2.57$ & 1.01 & 0.39 \\
\hline $\mathrm{WC}^{\mathrm{a}}(\mathrm{cm})$ & $100.93 \pm 11.00$ & $105.91 \pm 8.46$ & $106.00 \pm 8.31$ & $105.88 \pm 7.31$ & 1.59 & 0.20 \\
\hline $\mathrm{WHR}^{\mathrm{a}}$ & $0.92 \pm 0.35$ & $0.90 \pm 0.32$ & $1.03 \pm 0.19$ & $1.06 \pm 0.35$ & 1.18 & 0.32 \\
\hline
\end{tabular}

a Abbrivation: $\mathrm{VO}_{2} \mathrm{max}$, Oxygen Uptake; FVC, Forced Vital Capacity; FEV1, Forced Expiratory Volume in One Second; HbA1c, Glycosylated Haemoglobin; BMI: Body mass index; WC, Waist Circumference; WHR, Waist hip ratio

b significance at $P<0.05$.

${ }^{\mathrm{c}}$ Data are Presented as Mean \pm SD

Table 3. Pulmonary, Biochemical and Anthropometric Variables of Study Participants

\begin{tabular}{|c|c|c|c|c|c|c|c|c|c|}
\hline \multirow[t]{2}{*}{ Variables } & \multicolumn{2}{|c|}{ Baseline } & \multicolumn{2}{|c|}{$4^{\text {th }}$ Week } & \multicolumn{2}{|c|}{$8^{\text {th }}$ Week } & \multicolumn{2}{|c|}{$12^{\text {th }}$ Week } & \multirow[t]{2}{*}{ PValue } \\
\hline & Pare & Control & Pare & Control & Pare & Control & Pare & Control & \\
\hline \multicolumn{10}{|l|}{ Pulmonary } \\
\hline $\begin{array}{l}\mathrm{VO}_{2} \max ^{\mathrm{a}} \\
\mathrm{kg} / \mathrm{mL} / \mathrm{min}\end{array}$ & $21.32 \pm 5.33^{c}$ & $21.43 \pm 5.27$ & $23.19 \pm 4.82$ & $18.07 \pm 2.41$ & $26.05 \pm 4.58$ & $18.17 \pm 2.86$ & $28.64 \pm 4.88$ & $19.94 \pm 6.15$ & $0.001^{\mathrm{b}}$ \\
\hline FVC $^{a}$, Litres & $1.50 \pm 0.22$ & $1.81 \pm 0.82$ & $2.06 \pm 0.49$ & $1.80 \pm 0.77$ & $2.18 \pm 0.53$ & $1.78 \pm 0.73$ & $2.13 \pm 0.57$ & $2.08 \pm 0.68$ & $0.001^{\mathrm{b}}$ \\
\hline FEV $1^{a}$, Litres & $1.42 \pm 0.27$ & $1.39 \pm 0.56$ & $1.94 \pm 0.44$ & $1.47 \pm 0.57$ & $2.14 \pm 0.54$ & $1.61 \pm 0.53$ & $2.32 \pm 0.45$ & $1.48 \pm 0.55$ & $0.001^{\mathrm{b}}$ \\
\hline \multicolumn{10}{|l|}{ Biochemical } \\
\hline $\mathrm{HbA1}_{C}{ }^{\mathrm{a}}, \%$ & $7.38 \pm 1.23$ & $6.95 \pm 1.34$ & - & - & - & - & $6.07 \pm 0.86$ & $6.77 \pm 0.71$ & $0.001^{\mathrm{b}}$ \\
\hline \multicolumn{10}{|c|}{ Anthropometric } \\
\hline $\mathrm{BMI}^{\mathrm{a}}, \mathrm{kg} / \mathrm{m}^{2}$ & $31.10 \pm 1.20$ & $33.00 \pm 2.45$ & $27.79 \pm 3.27$ & $34.83 \pm 7.04$ & $29.97 \pm 11.96$ & $32.96 \pm 2.47$ & $28.73 \pm 3.16$ & $32.95 \pm 2.57$ & 0.41 \\
\hline $\mathrm{WC}^{\mathrm{a}}, \mathrm{cm}$ & $100.53 \pm 9.99$ & $100.93 \pm 11.00$ & $93.40 \pm 6.77$ & $105.91 \pm 8.46$ & $95.81 \pm 6.45$ & $106.00 \pm 8.31$ & $98.61 \pm 8.05$ & $105.88 \pm 7.31$ & $0.03^{b}$ \\
\hline $\mathrm{WHR}^{\mathrm{a}}$ & $0.96 \pm 0.03$ & $0.92 \pm 0.35$ & $0.97 \pm 0.05$ & $0.90 \pm 0.32$ & $0.93 \pm 0.10$ & $1.03 \pm 0.19$ & $0.96 \pm 0.11$ & $1.06 \pm 0.35$ & 0.38 \\
\hline
\end{tabular}

a Abbreviation: $\mathrm{VO}_{2}$ max, Oxygen Uptake; FVC, Forced Vital Capacity; FEV1, Forced Expiratory Volume in One Second; HbA1 ${ }_{\mathrm{c}}$ Glycosylated Haemoglobin; BMI, Body Mass Index; WC, Waist Circumference; WHR, Waist hip ratio

b Significance at $P<0.05$

${ }^{c}$ Data are Presented as Mean \pm SD

continue through the Weeks 8 and 12 of the intervention period. Mean HbA1c levels and waist circumference (Table 3) fell in PARE subjects compared with the control. There were significant differences in $\mathrm{VO}_{2}$ max, $\mathrm{FEV}_{1}, \mathrm{FVC}$, HbA1C, and WC. No significant difference was observed in BMI or WHR when the PARE group was compared with the control group.

Figure 1 shows a schematic of the post hoc analysis of the pulmonary variables in the subjects. The PARE and control groups differed in $\mathrm{VO}_{2}$ max and FEV1 at Weeks 4, 8 , and 12 and FVC differed at Weeks 4 and 8.

\section{Discussion}

The effect of PARE on pulmonary, anthropometric, and HbA1c variables in individuals with T2DM was assessed at specified points. PARE had significant therapeutic effects on pulmonary variables, HbA1c values, and waist circumference in T2DM subjects. Thes improvements support the findings of Ferdowsi et al.(28), who demonstrated significant improvements in FEV1 and FVC postexercise intervention. Baldi et al. (29) also reported significant

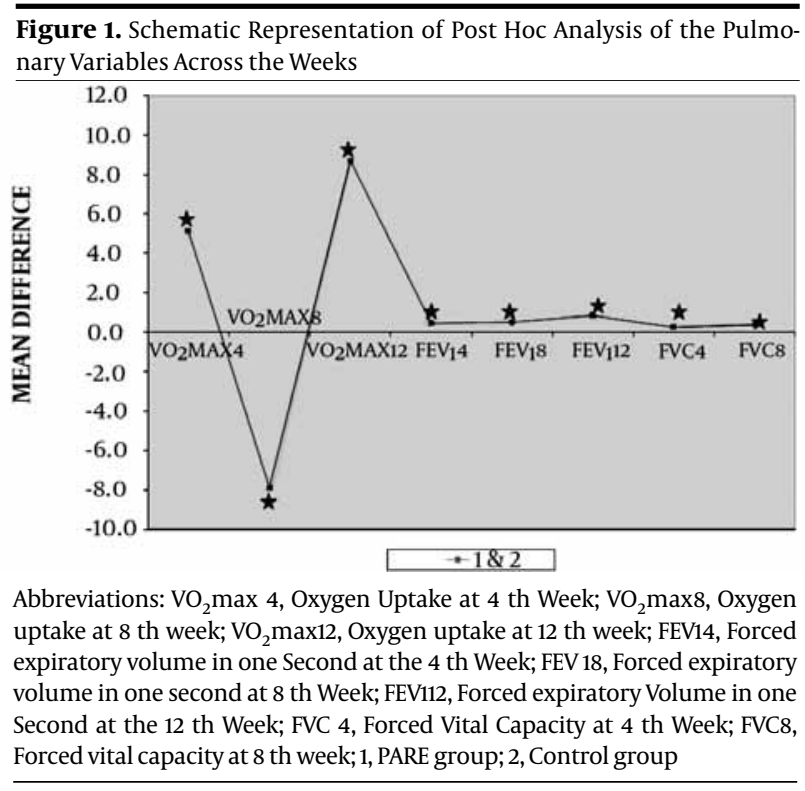

improvements in $\mathrm{VO}_{2} \max$. However, our findings contrasted of Jones and Magdalene (30), who reported no 
significant improvement in lung volume. The findings in our study may be attributable to the improvements in glucose metabolism that occur acutely and immediately after exercise, thus producing its effects, even 48 hours postexercise intervention, as reported by Davis et al., 2000 (13) and Kaminsky et al. (9). The result is good glucose control as consistent exercise sessions continue, since the subjects in this study performed PARE 3 times per week for 12 weeks ( 3 months) in the intervention period. This The exercise sessions might have probably enable adequate glucose control, which is usually measured over 3 months as HbA1c. Reduced lung volume and airflow limitation are chronic complications of T2DM. The severity of this decrease is related to glycemic exposure $(9,10)$.

Poor glucose control has been linked to microvascular complications and reduced ventilatory function of the lungs (10). Airflow limitation is a predictor of death in T2DM after adjusting for other recognized risk factors (11). The observed reduction in mean HbA1c in this study, which supports some studies $(31,32)$ but contrasts the findings of Bibi et al. (33), may have prompted the significant improvement in $\mathrm{VO}_{2} \mathrm{max}$, FVC, and FEV1 values. During aerobic exercise, whole-body oxygen consumption increases by as much as 20-fold, and even greater increases occur in the working muscles with additional resistance exercise (34). To meet its energy needs under these circumstances, skeletal muscle uses its own stores of glycogen and triglycerides at a tremendously increased rate, as well as free fatty acids (FFAs) derived from the breakdown of adipose tissue triglycerides and glucose released from the liver, leading to decreased blood glucose levels (29). With improved glucose control, microvascular complications and inflammation of lung tissue are averted, resulting in improved lung function, reflected by the improved FEV1, FVC, and $\mathrm{VO}_{2}$ max values in this study. The early improvement in pulmonary variables, as evidenced from the mean increase, may thus be attributed to the combined therapeutic effect of aerobic and resistance exercises. Improvements in cardiorespiratory function do not result from changes in the lung's ability to expand (29). In general, individuals with T2DM who exercise regularly do not experience changes in pulmonary function, such as the amount of air that is blown out after taking the largest breath possible (FVC) (29). However, FVC values improved.

The insignificant difference in BMI and WHR in this study are likely due to the fat composition of the subjects might being replaced by hypertrophied muscles, since resistance exercise, which was performed by the subjects, has hypertrophying effects, as reported by Carson and Wei, 2000 (35). Respiratory impairments in people with DM are attributed to increased BMI and WC, with subsequent loss of respiratory compliance and respiratory muscle strength (8). Improved pulmonary functions are partly attributed to increased respiratory muscle strength in a study (28). However, this study did not assess the fat composition of subjects or respiratory muscle strength; thus, we could not attribute the improvement in pulmonary functions to the changes in anthropometric variables (WC) for certain. Future research will be required to examine this association. However, the reduction in WC in subjects who performed strengthening exercises for their abdominal muscles, which are the major muscles of active expiration, may be an indication of reduced abdominal fat with improved muscle tone. Improved abdominal muscle strength may thus be speculated to occur in this scenario.

In summary, our study demonstrates that progressive weight aerobics and resistance exercise are beneficial therapeutic adjuncts for the management of T2DM. Periodic assessment of pulmonary functions after exercise should commence as early as 4 weeks postintervention, although, significant improvements might be expected after 8 weeks postintervention.

\section{Acknowledgements}

This study was partly funded by a grant from Doctoral Assistance Grant of the University of Lagos, Nigeria. We thank Dr. Anthonia Ogbera, and Dr O. A Fasanmade of the Endocrinology unit, Department of Medicine of LUTH and LASUTH, Lagos, Nigeria for support on patient recruitment and screening. Dr Adegoke of Chemical Pathology Department LUTH for analyzing the blood samples for HbA1c and all the patients who volunteered to participate in this study.

\section{Financial Disclosure}

There is no conflict of interest.

\section{Funding/Support}

This study was partly funded by the Doctoral Assistance Grant from the University of Lagos, Nigeria.

\section{References}

1. Bello-Sani F, Anumah F. Electrocardiographic abnormalities in persons with type 2 diabetes in Kaduna, Northern Nigeria. Int J Diabetes \& Metabolism. 2009;17:99-103.

2. Familoni O, Odusan O, Raimi T. The Relationship Between QT Intervals and Cardiac Autonomic Neuropathy in Nigerian Patients with Type 2 Diabetes Mellitus. Nigeria Med Practitioner. 2008;53 (4) :48-51.

3. National Institute of Health Publication. National Diabetes Statistics. No. 11-3892; 2011 [updated 2011]; Available rom: http://diabetes.niddk.nih.gov/dm/pubs/statistics/DM_Statistics.pdf.

4. Zimmet PZ, McCarty DJ, de Courten MP. The global epidemiology of non-insulin-dependent diabetes mellitus and the metabolic syndrome. J Diabetes Complications. 1997;11 (2):60-8.

5. Nyenwe EA, Odia OJ, Ihekwaba AE, Ojule A, Babatunde S. Type 2 diabetes in adult Nigerians: a study of its prevalence and risk factors in Port Harcourt, Nigeria. Diabetes Res Clin Pract. 2003;62 (3) :177-85.

6. Abubakari AR, Bhopal RS. Systematic review on the prevalence of diabetes, overweight/obesity and physical inactivity in Ghanaians and Nigerians. Public Health. 2008;122 (2):173-82.

7. Goldman MD. Lung dysfunction in diabetes. Diabetes Care. 2003;26 (6) :1915-8. 
8. Ozoh OB, Okubadejo NU, Chukwu CC, Bandele EO. Eligibility of Nigerians with type 2 diabetes mellitus for inhaled insulin. Nig QJ Hosp Med. 2010;20 (2):77-80.

9. Kaminski DM, Schaan BD, da Silva AM, Soares PP, Plentz RD, Dall'Ago P. Inspiratory muscle weakness is associated with autonomic cardiovascular dysfunction in patients with type 2 diabetes mellitus. Clin Auton Res. 2011;21 (1):29-35.

10. Davis TM, Knuiman M, Kendall P, Vu H, Davis WA. Reduced pulmonary function and its associations in type 2 diabetes: the Fremantle Diabetes Study. Diabetes Res Clin Pract. 2000;50 (2) :153-9.

11. McKeever TM, Weston PJ, Hubbard R, Fogarty A. Lung function and glucose metabolism: an analysis of data from the Third $\mathrm{Na}$ tional Health and Nutrition Examination Survey. Am J Epidemiol. 2005;161 (6) :546-56.

12. Di Loreto C, Fanelli C, Lucidi P, Murdolo G, De Cicco A, Parlanti N, et al. Make your diabetic patients walk: long-term impact of different amounts of physical activity on type 2 diabetes. Diabetes Care. 2005;28 (6):1295-302.

13. Davis WA, Knuiman M, Kendall P, Grange V, Davis TM. Glycemic exposure is associated with reduced pulmonary function in type 2 diabetes: the Fremantle Diabetes Study. Diabetes Care. 2004;27 (3) :752-7.

14. Laaksonen DE. Supplementum 1 Role Of Physical Exercise, Fitness And Aerobic Training In Type 1 Diabetic And Healthy Men In Relation To The Lipid Profile, Lipid Peroxidation And The Metabolic Syndrome. J Sports Sci Med. 2003;2 (1) :1-65.

15. Sigal RJ, Kenny GP, Boule NG, Wells GA, Prud'homme D, Fortier $\mathrm{M}$, et al. Effects of aerobic training, resistance training, or both on glycemic control in type 2 diabetes: a randomized trial. Ann Intern Med. 2007;147 (6):357-69.

16. Arora E, Shenoy S, Sandhu JS. Effects of resistance training on metabolic profile of adults with type 2 diabetes. Indian JMed Res. 2009;129 (5):515-9.

17. Fletcher B, Berra K, Ades P, Braun LT, Burke LE, Durstine JL, et al. Managing abnormal blood lipids: a collaborative approach. Circulation. 2005;112 (20):3184-209.

18. Topolski TD, LoGerfo J, Patrick DL, Williams B, Walwick J, Patrick MB. The Rapid Assessment of Physical Activity (RAPA) among older adults. Prev Chronic Dis. 2006;3 (4) :A118.

19. Osho OA, Abidoye RO, Owoeye OB, Akinfeleye AM, Akinbo SR. Physical activity level, nutritional intake, functional status and quality of life of geriatric individuals in Lagos, South-West, Nigeria: a cross sectional survey. Nig QJ Hosp Med. 2011;21 (1) :9-15.

20. Ramsbottom R, Kinch RF, Morris MG, Dennis AM. Practical application of fundamental concepts in exercise physiology. Adv Physiol Educ. 2007;31 (4) :347-51.

21. Jones AM, Doust JH. A $1 \%$ treadmill grade most accurately reflects the energetic cost of outdoor running.J Sports Sci. 1996;14 (4):321-7.

22. Quinn E. Treadmill vs. Outside Running: Which Is Best? Is Running on a Treadmill As Good As Running Outside? . 2010 [updated 2010]; Available rom: http://sportsmedicine.about.com/ od/tipsandtricks/a/treadincline.htm.

23. Adeniyi AF, Sanya AO, Fasanmade AA, Tujani B, Uloko AE. Association Betweenpulse Indexand Metabolic Syndrome In Individuals With Type 2 Diabetes Mellitus: Outcomeofatwelve-Weeks Therapeutic Exercise Programme. Nigeria J Med Rehab. 2007;12 (20):9-15.

24. Kluding PM, Singh R, Goetz J, Rucker J, Bracciano S, Curry N. Feasibility and effectiveness of a pilot health promotion program for adults with type 2 diabetes: lessons learned. Diabetes Educ. 2010;36 (4):595-602.

25. Society AT. Standardization of Spirometry, 1994 Update. American Thoracic Society. Am J Respir Crit Care Med. 1995;152 (3) :110736.

26. Kline GM, Porcari JP, Hintermeister R, Freedson PS, Ward A, McCarron RF, et al. Estimation of VO2max from a one-mile track walk, gender, age, and body weight. Med Sci Sports Exerc. 1987;19 (3) :253-9.

27. O’Dea K, Walker K, Simmons D, Garry Egger G, Mann J. National Evidence Based Guidelines for the Management of Type 2 Diabetes Mellitus Part 2. Primary Prevention of Type 2 Diabetes. The Australian Centre for Diabetes Strategies Prince of Wales Hospital, Sydney for the Diabetes Australia Guideline Development Consortium. Approved by the National Health and Medical Research Council. 2001.

28. Ferdowsi MH, Saiiari A, Valizadeh R, Gholamie A. The effect of eight week aerobic exercise on airway trachea indexes (FEV1, FVC, FEV1. FVC \& FEF25-75) and $\mathrm{vo}_{2}$ max level in overweighed male students of Ahvaz Payam Noor University. Procedia-Social and Behavioral Sciences. 2011;15:2848-52.

29. Baldi JC, Cassuto NA, Foxx-Lupo WT, Wheatley CM, Snyder EM. Glycemic status affects cardiopulmonary exercise response in athletes with type I diabetes. Med Sci Sports Exerc. 2010;42 (8) :1454-9.

30. Jones RL, Nzekwu MM. The effects of body mass index on lung volumes. Chest. 2006;130 (3) :827-33.

31. Gram B, Christensen R, Christiansen C, Gram J. Effects of nordic walking and exercise in type 2 diabetes mellitus: a randomized controlled trial. Clin J Sport Med. 2010;20 (5) :355-61.

32. Shenoy S, Arora E, Jaspal S. Effects of progressive resistance training and aerobic exercise on type 2 diabetics in Indian population. Int J Diabetes \& Metabolism. 2009;17:27-30.

33. Sigal RJ, Kenny GP, Wasserman DH, Castaneda-Sceppa C, White RD. Physical activity/exercise and type 2 diabetes. Diabet Care. 2006;29 (6):1433.

34. Irwin ML, Ainsworth BE, Mayer-Davis EJ, Addy CL, Pate RR, Durstine JL. Physical activity and the metabolic syndrome in a tri-ethnic sample of women. Obes Res. 2002;10 (10): 1030-7.

35. Carson JA, Wei L. Integrin signaling's potential for mediating gene expression in hypertrophying skeletal muscle. J Appl Physiol. 2000;88 (1) :337-43. 